\title{
Characteristics of the $\mathrm{AlON}-\mathrm{Al}_{2} \mathrm{O}_{3}$ Ceramic Coatings on the $\mathrm{Al} 2021$ Alloy by Electrolytic Plasma Processing
}

\author{
Kai Wang, Sang Sik Byeon, Geun Woo Kim, Keun Young Park, \\ Faheem Ahmed and Bon Heun Koo ${ }^{\dagger}$ \\ School of Nano \& Advanced Materials Engineering, Changwon National University, Changwon 641-773, Korea
}

(Received December 14, 2011 : Received in revised form March 9, 2012 : Accepted March 12, 2012)

\begin{abstract}
In this work, $\mathrm{AlON}-\mathrm{Al}_{2} \mathrm{O}_{3}$ coatings were prepared on Al2021 alloy by the electrolytic plasma processing (EPP) method. The experimental electrolytes include: $2 \mathrm{~g} / \mathrm{l} \mathrm{NaOH}$ as the electrolytic conductive agent, $10 \mathrm{~g} / 1 \mathrm{Na}_{2} \mathrm{AlO}_{2}$ as the alumina formative agent, and $0.5 \mathrm{~g} / 1 \mathrm{NaNO}_{2}, \mathrm{NaNO}_{3}$, and $\mathrm{NH}_{4} \mathrm{NO}_{3}$ as the nitride inducing agents. The effects of different nitrogen inducing agents were studied by a combined compositional and structural analyses of the ceramic coatings carried out by Xray diffractometry (XRD) and scanning electron microscopy (SEM) for the specimens EPP-treated at room temperature for 15 min under a hybrid voltage of $260 \mathrm{DC}$ along with an AC $50 \mathrm{~Hz}$ power supply $(200 \mathrm{~V})$. Microhardness tests and wear tests were carried out to correlate the evolution of the microstructure and the resulting mechanical properties. Potentiodynamic polarizations and immersion corrosion tests were carried out in $3.5 \mathrm{wt} \% \mathrm{NaCl}$ water solutions under static conditions in order to evaluate the corrosion behavior of the coated samples. The results demonstrate that $\mathrm{NaNO}_{2}$ is proven to be a good nitrogen inducing agent to produce high quality $\mathrm{AlON}-\mathrm{Al}_{2} \mathrm{O}_{3}$ ceramic coatings.
\end{abstract}

Key words electrolytic plasma processing, $\underline{\mathrm{Al}}_{2} \underline{\mathrm{O}}_{3}-\mathrm{AlON}$, ceramic coating, aluminum alloy, nitrogen inducing agents.

\section{Introduction}

AlON with spinel phase is a unique material with many excellent properties which make it useful in various applications. It has been reported that AlON can be produced by several techniques such as sintering, reaction sintering, hot-pressing, hot isostatic pressing (HIP), selfpropagating high-temperature synthesis (SHS) and plasma arc synthesis. ${ }^{1-3)}$ However, all the traditional techniques require special equipments to provide high temperature and high pressure, and carefully previous powder preparation, which are complicated and have high economic costs. The formation of the various polytypoids also makes the interpretation of those processings difficult. Nowadays, the industrial society has a fierce demand for a new technique, with simple serviceability and low economic costs to replace those old techniques. The combination of plasma arc synthesis and plasma electrolytic deposition is hopeful to overcome this problem, which can produce AlON under low voltage and low temperature.

It is also reported that AlON films can be prepared by various chemical vapor deposition. ${ }^{4)}$ However, thin film makes its extensive application range limited and complicated. Electrolytic plasma processing (EPP), also called plasma electrolysis deposition (PED), has attracted great

'Corresponding author

E-Mail : bhkoo@changwon.ac.kr (B. H. Koo) interest and was studied widely for its high efficiency of fabricating ceramic coatings with exceptional properties on light metals (Al, $\mathrm{Mg}$ and $\mathrm{Ti}$ etc.). ${ }^{5-7)}$ Seldom reports mentioned about the EPP process to prepare AlON contained coatings. In this paper, the effect of nitrogen inducing agent on the characteristics of the coatings produced by EPP treatment was studied.

\section{Experimental Procedure}

Column samples (D $20 \mathrm{~mm} \times \mathrm{H} 30 \mathrm{~mm}$ ) of Al2021 alloy (Cu, 5.8-6.8 wt.\%; Mg, 1.2-1.8 wt.\%; Si, 0.5 wt.\%; Fe, 0.5 wt.\%, Zn, 0.1 wt.\%; Mn, 0.2-0.4 wt.\%; Ti, 0.15 wt.\% and $\mathrm{Al}$, balance) were used as the substrates. All the samples were polished to a uniform surface roughness of $0.1 \pm$ $0.05 \mu \mathrm{m}$, degreased with acetone and alcohol in ultrasonic bath, and then immersed in the electrolyte for EPP treatment. An EPP coating unit designed and built by the authors has been employed in the present study, which mainly consists of a power supply unit, a bath container and a cooling system. The metallic samples immersed in the electrolyte were used as the anode and stainless steel was used as the counter electrode. Throughout the experiment, the temperature of the electrolyte was maintained constant at approximately $25 \pm 2^{\circ} \mathrm{C}$ using a cooling system. The electrolysis environment was an aqueous electrolyte containing $10 \mathrm{~g} / 1 \mathrm{NaAlO}_{2}, 2 \mathrm{~g} / \mathrm{l} \mathrm{NaOH}$, and $0.5 \mathrm{~g} / 1 \mathrm{NaNO}_{2}$, $\mathrm{NaNO}_{3}$ or $\mathrm{NH}_{4} \mathrm{NO}_{3}$ divided into three groups (Table 1). 
Table 1. Electrolyte composition of different nitrogen inducing agents.

\begin{tabular}{clcc}
\hline Group No. & \multicolumn{3}{c}{ Electrolyte Composition } \\
\hline 1 & $10 \mathrm{~g} / 1 \mathrm{NaAlO}_{2}$ & $2 \mathrm{~g} / \mathrm{l} \mathrm{NaOH}$ & $0.5 \mathrm{~g} / 1 \mathrm{NaNO}_{2}$ \\
2 & $10 \mathrm{~g} / 1 \mathrm{NaAlO}_{2}$ & $2 \mathrm{~g} / \mathrm{l} \mathrm{NaOH}$ & $0.5 \mathrm{~g} / 1 \mathrm{NaNO}_{3}$ \\
3 & $10 \mathrm{~g} / 1 \mathrm{NaAlO}_{2}$ & $2 \mathrm{~g} / 1 \mathrm{NaOH}$ & $0.5 \mathrm{~g} / 1 \mathrm{NH}_{4} \mathrm{NO}_{3}$ \\
\hline
\end{tabular}

Samples were rinsed with distilled water after EPP procedures. The different phases present in the coatings were investigated with X-ray diffractometer (XRD) $\left(\mathrm{Cu} \mathrm{K} \mathrm{K}_{\alpha}\right.$ radiation) using Philips- $X$ 'Pert system and the scans were performed with $0.02^{\circ} \theta$ step size in the $2 \theta$ range of 20 $90^{\circ}$. The microstructure of surfaces and cross sections of samples by different nitrogen inducing agents were examined by a JSM 5610 scanning electron microscopy (SEM). Prior to SEM analysis, all the samples detected by SEM were sputtered with a thin gold layer in order to prevent surface charging effects. The microhardness of the coating layers in 10 different places was measured by a VLPAK2000 Mitutoyo hardness test machine using 0.1 $\mathrm{N}$ load with a $30 \mathrm{~s}$ dwell time, and then the average microhardness was calculated and reported.

The AC amplitude was slowly increased to $200 \mathrm{~V}$ to maintain the current density at $6 \mathrm{dA} / \mathrm{cm}^{2}$ throughout the experiment, afterwards the DC value was increased gradually with time till $260 \mathrm{~V}$ so as to maintain the reset current density even as the coating thickness gradually increased. During the EPP process, plenty amount of water vapor was produced by the exothermal EPP reaction, and enhance the plasma spark across the whole substrate.

In order to investigate the anti-abrasion properties of the oxide coatings, dry ball on disk wear tests were carried out by a PD-102 wear test machine. Samples to be tested are held horizontally against a GCr15 stainless steel ball (6 $\mathrm{mm}$ diameter). The steel ball rotated on the sample at a constant speed of $200 \mathrm{rev} . / \mathrm{min}$ in a $10 \mathrm{~mm}$ diameter trace. The tested samples are subjected to a normal perpendicular force of $600 \mathrm{gf}$ against the steel ball and the test time was set up to 3600 s.

Potentiodynamic polarization tests were performed by a Gamry Instrument (USA/CMS 1058). The test electrolyte is consisted of a $3.5 \mathrm{wt} \%(0.6 \mathrm{M}) \mathrm{NaCl}$ solution, naturally aerated and at a temperature of $20^{\circ} \mathrm{C}$; the $\mathrm{pH}$ of the solution (about 6.5) was not controlled, and the solution was not deaerated. A saturated calomel electrode (SCE) is used as the reference electrode, and a graphite rod served as the counter electrode for current measurement. The potential is increased from $-2.5 \mathrm{~V}$ to $4.5 \mathrm{~V}$ vs. open circuit potential with a scanning rate of $5 \mathrm{mV} / \mathrm{s}$; all potentials are given with respect to the SCE. The working surface of each specimen, polished to a final finish with $1 \mu \mathrm{m}$ diamond paste, was mounted in the electrochemical cell to allow the surface area $\left(1.1 \mathrm{~cm}^{2}\right)$ to be accessed by the test solution. Corrosion current densities were determined by linear extrapolation of the polarization curves up to $\pm 50 \mathrm{mV}$ from the corrosion potential.

\section{Results and Discussion}

Fig. 1 illustrates the surface features of the EPP-treated Al2021 alloy in different nitrogen inducing agents contained electrolytes. The $\mathrm{AlON}-\mathrm{Al}_{2} \mathrm{O}_{3}$ coatings present uniformly distributed pancake like structures resulted by the plasma discharge channels in these three groups. While the size of pancake like structure for $\mathrm{NH}_{4} \mathrm{NO}_{3}$ induced electrolyte of Group 3 is smallest, but the diameter of the discharge channel is largest during those three nitrogen inducing agents. Obvious cracks can be found in $\mathrm{NaNO}_{3}$ induced samples of Group 2. Large pancake like structure with small discharging channel and cracks can hardly be found in $\mathrm{NaNO}_{2}$ induced samples of Group 1. The surface defects, such as cracks and cavities would deter the characteristics of the coatings.

The cross-sectional SEM images of coatings EPP-treated in different nitrogen induced electrolytes are shown in Fig. 2. As the function of high temperature plasma sparks, surface aluminum meltdown and flew outwards through the discharging channels, and then oxidise to form $\gamma-\mathrm{Al}_{2} \mathrm{O}_{3}{ }^{8}$ ) With the participation of nitrogen from the electrolytes, the $\gamma-\mathrm{Al}_{2} \mathrm{O}_{3}$ would react with nitrogen forming $\mathrm{AlON}$ phase in the high temperature and pressure plasma area. ${ }^{9}$ At the same time, $\gamma-\mathrm{Al}_{2} \mathrm{O}_{3}$ would transform to $\alpha-\mathrm{Al}_{2} \mathrm{O}_{3}$ at a sharp temperature gradient when the hot $\gamma-\mathrm{Al}_{2} \mathrm{O}_{3}$ phase emerged from the channels and rapidly quenched at the interface between electrolyte and substrates. The generation and growth of AlON phase and transformation of $\gamma-$ to $\alpha-\mathrm{Al}_{2} \mathrm{O}_{3}$ phase resulted in the growth of the ceramic coatings. It is found that cracks formed in $\mathrm{NaNO}_{3}$ induced samples of Group 2, whereas the coatings of $\mathrm{NH}_{4} \mathrm{NO}_{3}$ induced sample
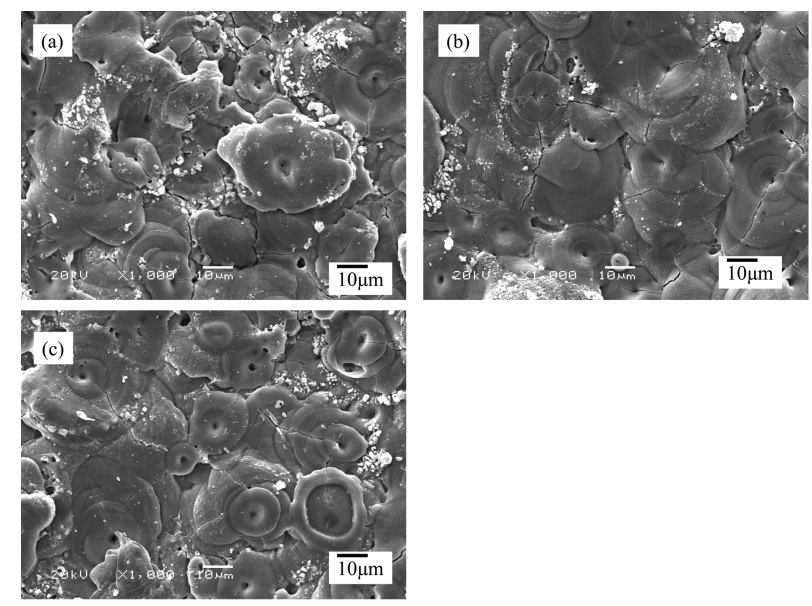

Fig. 1. Surface morphologies of the coatings EPP treated in a) $\mathrm{NaNO}_{2}$, b) $\mathrm{NaNO}_{3}$ and c) $\mathrm{NH}_{4} \mathrm{NO}_{3}$ induced electrolytes. 

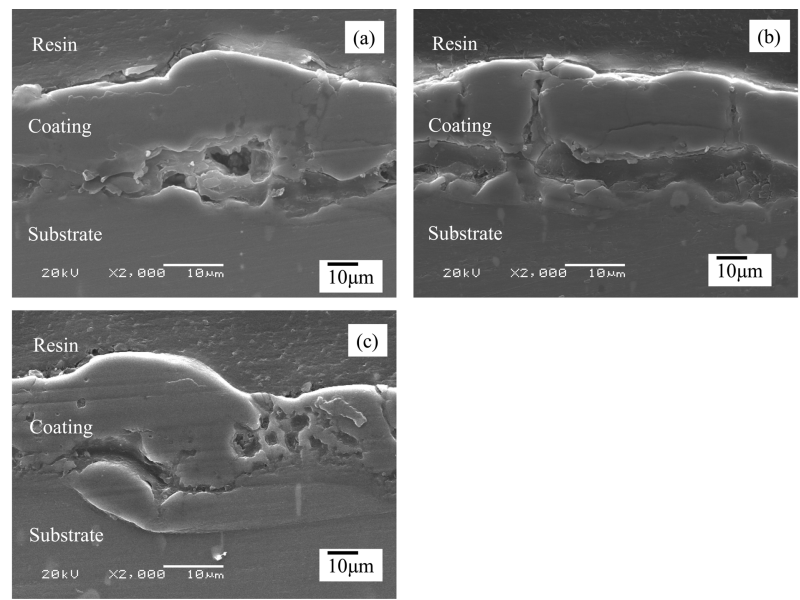

Fig. 2. Cross sectional morphologies of the coatings EPP treated in a) $\mathrm{NaNO}_{2}$, b) $\mathrm{NaNO}_{3}$ and c) $\mathrm{NH}_{4} \mathrm{NO}_{3}$ induced electrolytes.

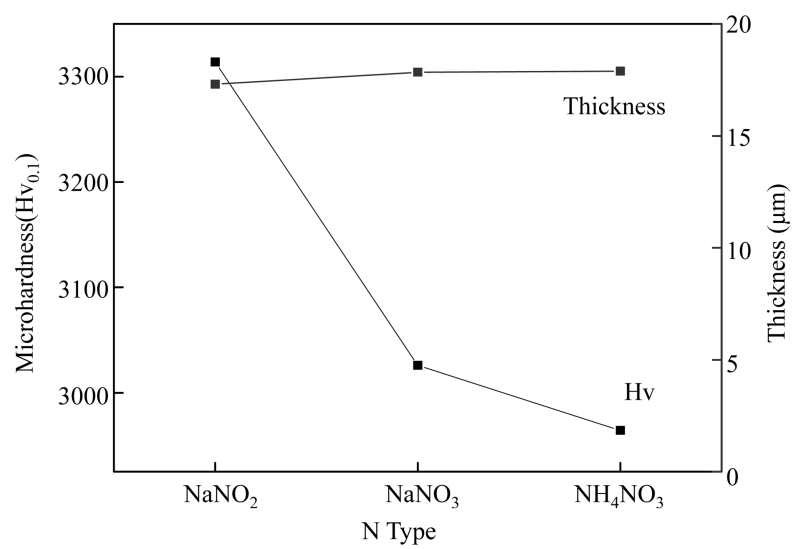

Fig. 3. Microhardness and thickness values of the coatings EPP treated in different nitrogen induced electrolytes.

of Group 3 are more porous. Some cavities are observed between the ceramic coating and substrates in $\mathrm{NaNO}_{2}$ induced samples of Group 1, which may reduce the bonding force and anti-corrosive properties of the coated samples.

The microhardness tests indicated that EPP coatings on the Al2021 alloy in all nitrogen induce electrolytes exhibit extremely high hardness, as shown in Fig. 3. The hardest coating can be obtained in $\mathrm{NaNO}_{2}$ induced electrolytes, which can reach above $3300 \mathrm{Hv}_{0.1}$. For the porous structures of the coatings prepared in $\mathrm{NH}_{4} \mathrm{NO}_{3}$ induced electrolytes and low content of AlON phase in $\mathrm{NaNO}_{3}$ induced electrolytes, the microhardness decreased to $2904 \mathrm{Hv}_{0.1}$ and $3026 \mathrm{Hv}_{0.1}$. It is obvious that the $\mathrm{Al}_{2} \mathrm{O}_{3}-\mathrm{AlON}$ ceramic coatings can significantly improve the strength of the coating as compared to other deposition methods ${ }^{5)}$ which make them useful for industrial applications.

The phase analysis of the ceramic coatings by XRD on the A12021 alloy prepared in different electrolytes is presented in Fig. 4. It can be clearly seen from Fig. 4 that

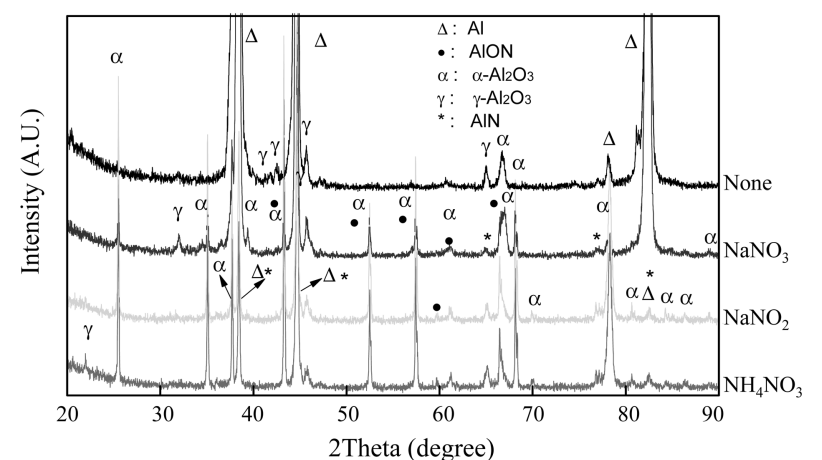

Fig. 4. XRD partterns of EPP-treated coatings in different nitrogen induced and none-nitrogen induced electrolytes.
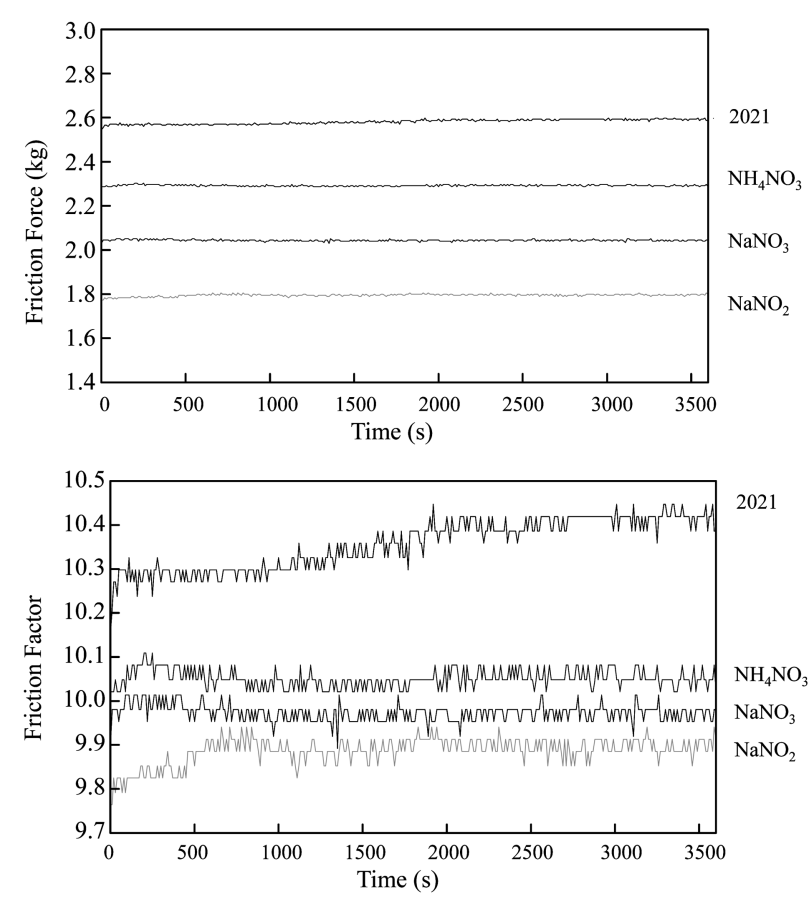

Fig. 5. Friction forces and factors of coated samples (with different nitrogen inducing agents) and uncoated Al2021 alloy substrate.

the strong diffraction peaks of $\mathrm{Al}$ are observed. Besides, the peaks of $\mathrm{AlN}$ overlape with $\mathrm{Al}$, as may reduce the intensity of the $\mathrm{Al}$ peaks. The typical peaks of ceramic coatings is consisted of $\alpha-\mathrm{Al}_{2} \mathrm{O}_{3}, \gamma-\mathrm{Al}_{2} \mathrm{O}_{3}$ and $\mathrm{AlON}$ according to the XRD patterns.

Fig. 5 shows the friction forces and friction factors of different nitrogen induced samples during the wear tests. It is obvious that all the EPP coated samples present low friction forces and factors, which shows that the ceramic coated sample possesses good anti-abrasive properties. Among all the nitrogen induced samples, the $\mathrm{NaNO}_{2}$ induced sample has the lowest friction force and factors. The best anti-abrasive property of $\mathrm{NaNO}_{2}$ induced sample is attributed to its hardest coating.

The potentiodynamic polarization curves of coated sam- 


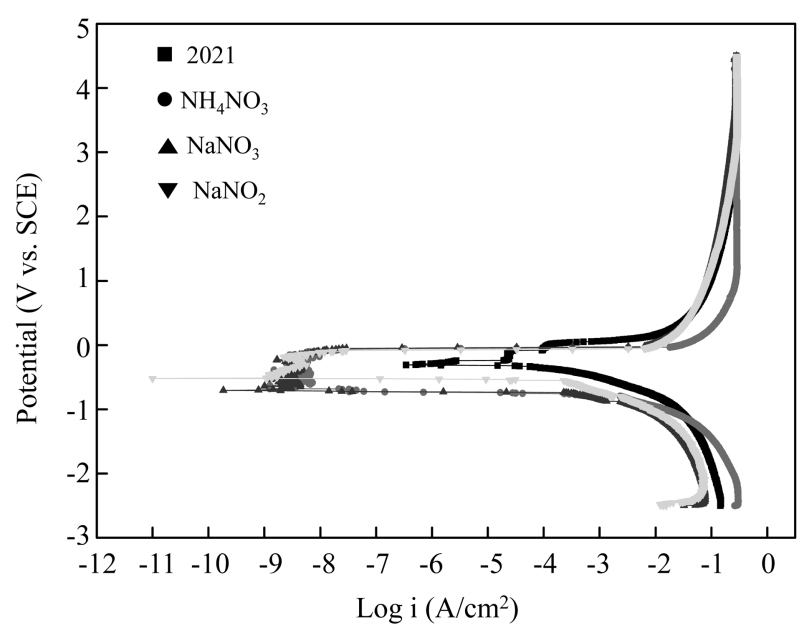

Fig. 6. Potentiodynamic polarization curves of coated samples (with different nitrogen inducing agents) and uncoated Al2021 alloy substrate.

ples (with different nitrogen inducing agents) and uncoated Al2021 alloy substrate are shown in Fig. 6. It is found that the corrosion potential of all the coated sample $(-0.5056$ $\mathrm{V},-0.6222 \mathrm{~V}$, and $-0.7111 \mathrm{~V}$ for $\mathrm{NaNO}_{2}, \mathrm{NaNO}_{3}$ and $\mathrm{NH}_{4} \mathrm{NO}_{3}$ induced samples, respectively), is lower than that of the uncoated Al2021 alloy substrate $(-0.1778 \mathrm{~V})$. However, only the corrosion current of the EPP-coated sample with inducing $\mathrm{NaNO}_{2}\left(0.003914 \mathrm{~A} / \mathrm{cm}^{2}\right)$ is lower than that of the uncoated sample $\left(0.009183 \mathrm{~A} / \mathrm{cm}^{2}\right)$, which showed that the EPP-coated sample with inducing $\mathrm{NaNO}_{2}$ can prevent the corrosion, thus increase the anti-corrosion resistance of the samples. However, the other EPP-coated samples with inducing $\mathrm{NaNO}_{3}$ and $\mathrm{NH}_{4} \mathrm{NO}_{3}(0.01869 \mathrm{~A} /$ $\mathrm{cm}^{2}$ and $0.027826 \mathrm{~A} / \mathrm{cm}^{2}$ respectively) are higher than that of the uncoated sample, which present higher corrosion speed as to worse anti-corrosive properties.

\section{Conclusion}

EPP processes were carried out in alkaline aluminate with different nitrogen induced electrolytes on Al2021 alloy substrates for $15 \mathrm{~min}$ under a hybrid voltage $(260 \mathrm{~V}$ DC value combined with $200 \mathrm{~V}$ AC amplitude). The surface morphologies of EPP $\mathrm{Al}_{2} \mathrm{O}_{3}$-AlON coatings present pancake structures in all types of nitrogen induced electrolytes. The phases of the coating are consisted of $\mathrm{AlON}, \gamma-\mathrm{Al}_{2} \mathrm{O}_{3}$, $\alpha-\mathrm{Al}_{2} \mathrm{O}_{3}$ and AlN. The property results show that $\mathrm{NaNO}_{2}$ is a proper nitrogen inducing agent to produce hard, antiabrasive and anti-corrosive ceramic $\mathrm{AlON}-\mathrm{Al}_{2} \mathrm{O}_{3}$ coating on the Al2021 alloy by EPP method.

\section{Acknowledgement}

This work was supported by the National Research Foundation of Korea (NRF) grant funded by the Korea government (MEST) (No.2011-0030802). This work was also supported by the MKE (The Ministry of Knowledge Economy), Korea, under the ITRC (Information technology Research Centre) support program supervised by the NIPA (National IT Industry promotion Agency) (NIPA-2012H0301-12-2009).

\section{References}

1. J. W. McCauley, P. Patel, M. Chen, G. Gilde, E. Strassburger, B. Paliwal, K. T. Ramesh and D. P. Dandekar, J. Eur. Ceram. Soc., 29, 223 (2009).

2. D. Zientara, M. M. Bucko and J. Lis, J. Eur. Ceram. Soc., 27, 775 (2007).

3. S. Balasubramanian, R. K. Sadangi, V. Shukula, B. H. Kear and E. Niesz, Ceram. Trans., 148, 83 (2004) .

4. B. H. Kim, S. R. Lee, K. M. Ahn, S. M. Kang, Y. H. Yang and B. T. Ahn., Kor. J. Mater. Res., 19(1), 37 (2009) (in Korean).

5. A. L. Yerokhin, X. Nie, A. Leyland, A. Matthews and S. J. Dowey, Surf. Coating. Tech., 122, 73 (1999).

6. X. Nie, A. Leyland, H. W. Song, A. L. Yerokhin, S. J. Dowey and A. Matthews, Surf. Coating. Tech., 116-119, 1055 (1999).

7. G. Sundararajan and L. R. Krishna, Surf. Coating. Tech., 167, 269 (2003).

8. S. G. Xin, L. X. Song, R. G. Zhao and X. F. Hu, Surf. Coating. Tech., 199, 184 (2005).

9. P. Tabary, C. Servant and J. A. Alary, J. Eur. Ceram. Soc., 20, 913 (2000). 